\title{
Editorial
}

\section{Buyers in business-to-business branding}

While there are many similarities and parallels that can be drawn between the business-to-consumer (B2C) and business-to-business (B2B) branding relationships, there are also key elements that vary between these branding environments that warrant further academic and professional investigation. Where the average person is surrounded by business branding, they often are unaware of its impact versus their myriad of experiences with consumer branding.

Consider the typical cocktail party situation where two separate pairs of people are having a discussion. One pair includes a brand manager for a consumer products company that markets skin creams and hair care products. The other pair includes a brand manager for an electronics company that markets internal system components for companies making switching devices; the switching devices are marketed to companies that manufacture telecommunications equipment; and the telecommunications equipment is for companies that market to wireless network providers, who in turn market to end consumers. Where, between the first pair, the conversation might last a while, often in the second pair the person talking to the electronics brand manager quickly looks for another glass of merlot.

In much the same way, branding literature is abundant in its commentary on the workings of the B2C branding relationship. The methodologies are often easier to understand and to illustrate. The major driver of any economic activity, however, continues to be B2B relationships. Therefore, this edition of the Journal of Brand Management further investigates the $\mathrm{B} 2 \mathrm{~B}$ branding environment, drawing where possible on the parallels with B2C experiences, but also highlighting any unique features of the endeavour.

In both the $\mathrm{B} 2 \mathrm{C}$ and $\mathrm{B} 2 \mathrm{~B}$ arenas competition is fierce, fast moving and professional. Consumers and businesses alike are increasingly better-informed savvy purchasers, with a high degree of confidence in their decision-making capabilities. There is no doubt that brand managers in this environment have their work cut out for them creating a differentiated, relevant and credible space for their brands to operate in.

A key area distinguishing the practice of $\mathrm{B} 2 \mathrm{C}$ versus $\mathrm{B} 2 \mathrm{~B}$ brand management is the nature of the purchasing process. Often, in the $\mathrm{B} 2 \mathrm{C}$ sector, the buying process is one to one. It is noted that there are often societal and image factors and a channel relationship bringing more influences into the decision process, but for the sake of schematics it is often - as the discipline is named - $\mathrm{B} 2 \mathrm{C}$ relationships.

The B2B purchasing process, however, is often a more complex procedure involving multiple decision makers and buying teams. Often the people involved in making a decision on a brand are located in different departments, functions and locations. Furthermore, in today's global, cross- 
functional team environment, the people needing to be aware, informed and possessing a high degree of understanding of a brand's positioning are often separated by cultures and by oceans.

An improved understanding of the types of buyers encountered in B2B environments is helpful. In their book, 'Strategic Selling', Miller and Heiman provide a useful model of the types of buyers involved in a typical B2B purchasing relationship. These buyers include:

- Economic buyer: This buyer releases the money and has ultimate power of veto in the selection of the purchased brand.

- Technical buyer: The role of this buyer is to screen out various brands from consideration. This type of buyer makes judgments about the technicalities of a product or service versus another offering as a way of screening out vendors and brands.

- User buyer: This buyer judges the impact on the job. The user buyer considers a brand in terms of who within the company will personally use or supervise the use of a product or service.

- Coach: This buyer is an internal guide who helps direct an outside business on the internal intricacies of making a specific sale.

Through understanding the purchasing processes involved in $\mathrm{B} 2 \mathrm{~B}$ transactions, and the unique types of buyers involved, the professional brand manager can improve their odds of differentiating their brand in this multifarious environment. Many B2B purchases are substantial in their scale and often involve a great deal of risk on the part of the buyer. Therefore, proper positioning of relevant brand characteristics, in a credible way, to each unique buying influence, poses a significant challenge for the $\mathrm{B} 2 \mathrm{~B}$ marketer, but also offers huge rewards when done properly. As brands are often perceived as mental short-cuts from the buyer's perspective, reinforcement of value, quality, risk reduction and performance are often hallmarks of successful B2B branding campaigns.

As in the B2C space, crafting a strong brand presence in the $\mathrm{B} 2 \mathrm{~B}$ world helps establish a barrier to entry and an entry over other's barriers by building a solid platform for new product or service launches. It helps establish premium prices and increases one's ability to attract top talent and valuable business partners.

I thank all who have answered the call for papers for this special B2B edition of the Journal of Brand Management. I also encourage continued academic and practical exploration of this valuable topic for the benefit of business process, to achieve improvements in classical brand management, and for the betterment of B2B brand managers at cocktail parties everywhere.

\section{Reference}

(1) Miller, R. and Heiman, S. (1985) 'Strategic Selling', Miller Heiman Associates Inc., Time Warner Books, New York, pp. 97-98.

Randall S. Rozin Special Issue Editor E-mail: randall.rozin@dowcorning.com 